\title{
Metodologias ativas na educação: problemas, projetos e cooperação na realidade educativa
}

\author{
Active methodologies in education: problems, pro- \\ jects and cooperation in educational reality
}

\author{
JEFERSON ANTUNES \\ Universidade Federal do Ceará
}

VERÔNICA SALGUEIRO DO NASCIMENTO

Universidade Federal do Ceará

ZULEIDE FERNANDES DE QUEIROZ

Universidade Regional do Cariri

\begin{abstract}
Resumo: As reflexões contemporâneas sobre os processos educativos relacionam a necessidade de mudança didática através da educação crítica, contextualizada e significativa, no que as metodologias ativas têm contribuído para a discussão. Como se dão estas práticas? Quais seus limites e possibilidades? Quais outras aproximações teóricas podem nos ajudar a melhor compreender as possibilidades do uso destas metodologias? O presente estudo tem por objetivo descrever as metodologias de aprendizagem baseadas em projetos e em problemas. Seus demais objetivos são apresentar as diferenças entre as duas metodologias e realizar uma análise de aproximação teórica entre elas e a aprendizagem cooperativa. A partir de uma revisão bibliográfica, entendemos que as duas metodologias estudadas se apresentam como vantajosas para os educadores que desejam fomentar a autonomia, a colaboração e a contextualização dos conteúdos a serem explorados, com forte imbricação na característica da cooperação.
\end{abstract}

Palavras-chave: Metodologias ativas. Aprendizagem baseada em problemas. Aprendizagem baseada em projetos. Aprendizagem cooperativa.

\begin{abstract}
Contemporary reflections on educational processes suggest the need for an educational change, which should be more contextual and meaningful, to which contribute active methodologies. How are these methodologies conceived? What are their limits and possibilities? What other theoretical approaches can help better understand the possibilities of using these methodologies? The present study aims to describe the methodologies of project-based learning and problem-based learning. Other objectives are presenting the difference between the two methodologies, and undertaking a theoretical analysis of methods with cooperative learning. From a bibliographical review, we understand that the methods studied are presented as advantageous for educators who wish to foster autonomy, collaboration and contextualization of the contents to be explored, with a strong overlap in the cooperative feature.
\end{abstract}

Keywords: Active methodologies. Problem based-learning. Project based-learning. Cooperative learning.

ANTUNES, Jeferson; NASCIMENTO. Verônica Salgueiro do; QUEIROZ, Zuleide Fernandes de. Metodologias ativas na educação: problemas, projetos e cooperação na realidade educativa. Informática na Educação: teoria \& prática, Porto Alegre, v. 22 , n. 1 , p. 111-127, jan./abr. 2019. 


\section{Introdução}

A educação contribui para a formação humana, possibilitando o reconhecimento de aspectos culturais constitutivos da vida, ela não é a prática especializada do ensino e tão pouco sua venda, mas uma atitude política que requer técnica e arte para uma formação integral do ser humano (MORIN; CIURANA; MOTTA, 2003; FREIRE, 1996).

Preocupados com os rumos que a educação toma, vários pesquisadores-professores ${ }^{1}$ alertam para a necessidade de revisão no paradigma educacional, salientando a necessidade de repensar a educação apenas como a transmissão catedrática do conhecimento, a homogeneização de saberes e pessoas. Eles buscam renovar métodos através da reflexão acerca do campo pedagógico.

A partir destas reflexões introdutórias sobre o pensamento educacional, o profissional da educação crítica se apresenta como agente de mudança, da formação de consciência em que "a instituição de ensino deve superar os limites do ensino tradicionalista, de modo a estar aberta às vivências em sala de aula e a prática da cidadania" (CALDEIRA; GODOY; MORALES, 2012, p. 05) que possibilitem ao educando o contato com o mundo à sua volta de forma significativa e contextualizada.

Neste sentido, as metodologias ativas procuram responder às demandas solicitadas, favorecendo a autonomia, o trabalho em grupo e as práticas sociais, inter-relacionando a produção do conhecimento, sua aquisição e a vida cotidiana. As metodologias ativas são práticas pensadas para a atividade de sala de aula visando desenvolver processos de ensinoaprendizagem através de desafios concretos a serem superados, advindos das atividades essenciais da prática social, sejam elas reais ou simuladas, sendo planejadas por professores e estudantes, em que profissionais da educação atuam no fomento à atividades em que estudantes possam examinar, relacionar e refletir sobre sua própria realidade e conhecimentos (BENDER, 2014; BARBOSA; MOURA, 2013; BERBEL, 2011).

As proposições didáticas contidas nas metodologias ativas condizem com atividades pedagógicas em sala de aula que visem a construção do conhecimento colaborativo e a aprendizagem prática, proporcionadas por objetivos pedagógicos delimitados para estas finalidades.

Existe um vasto leque de possibilidades nas metodologias ativas, no entanto, despontam no cenário da educação a aprendizagem baseada em problemas (ABPROB) e a aprendizagem baseada em projetos (ABPROJ), por serem, justamente, atividades mais propositivas à contextualização e cheias de significado.

Como se dão estas práticas? Quais seus limites e possibilidades? O que o educador necessita conhecer para a aplicação dos métodos? Qual a diferença entre estes métodos? Estas perguntas/problemas podem fazer parte do ideário de qualquer professor-pesquisador que deseja a aplicação de tais instrumentos didáticos, servindo de partida para essa discussão.

O presente artigo tem como objetivo principal descrever as metodologias de aprendizagem baseadas em projetos e em problemas, além disso, como demais objetivos, apresentamos as diferenças entre as duas metodologias e realizamos uma análise de aproximação teórica entre os métodos e a aprendizagem cooperativa (ACOOP) como abordagem do processo ensinoaprendizagem.

Para isso, nos cercamos da bibliografia existente, dialogando com vários autores, sejam teóricos, professores-pesquisadores e entusiastas, através da reflexão sobre artigos, livros e relatos de experiência que estudam e exploram o tema.

\footnotetext{
${ }^{1}$ Destacamos as obras de Paulo Freire, Pedro Demo, Moacir Gadotti, Demerval Savianni, Selma Guarrido Pimenta, Edgar Morin e José Carlos Libâneo, como importantes para o entendimento da questão levantada.
} 
Desta forma, pretendemos contribuir com os profissionais da educação interessados no tema e nas possibilidades de aplicação dos métodos escolhidos para este estudo, para que possam conhecê-los, refletir sobre seus limites e possibilidades, apresentando um aporte que possa embasar sua tomada de decisão para escolha ou não destas interações didáticas em sala de aula, relacionando o uso sistemático das metodologias com possíveis abordagens cooperativas para se repensar também o próprio processo.

\section{Metodologia}

Para este estudo, utilizamos o método bibliográfico (CRESWELL, 2010), através da seleção e revisão de artigos, livros e relatos de experiência relacionados aos temas explorados na base de dados Google Scholar, dando preferência a construção do conhecimento de autores e autoras brasileiros em vista a compreensão do tema em um aporte mais próximo a nossa realidade, visando apresentar concepções teóricas e abordagens sistematizadas por pares.

Recuperados, a partir da base de dados Google Scholar, em duas pesquisas separadas, com os termos aprendizagem baseada em problemas e aprendizagem baseada em projetos, nos últimos seis anos, sendo selecionados os primeiros cinco relatos de experiência para cada palavra-chave da recuperação de dados, visando apresentar um resumo dos resultados de experiências de aplicação de ambos os métodos.

\section{Aprendizagem baseada em problemas/projetos na educação}

A ABPROB e a ABPROJ são duas metodologias ativas que vêm sendo utilizadas na educação, sendo os relatos destas experiências muito ricos para que nós educadores possamos compreender de que forma as metodologias ativas contribuem para a discussão destes temas de forma cooperativa.

Na década de 1960, a ABPROB surge no Canadá, Universidade de McMáster (Hamilton), aplicada inicialmente no currículo das escolas de Medicina, e se torna o sistema padrão de Didática na Universidade de Aalborg, em 1974, visando garantir uma relação dialética entre a teoria e a prática profissional; no Brasil, década de 1990, a metodologia foi implementada no currículo dos cursos de medicina na Universidade de Marília (São Paulo) e na Universidade de Londrina (Paraná) (BARBOSA; MOURA，2013; ENEMARK; KJAERSDAM, 2016; DECKER; BOUHUIJS, 2016).

Nesse método, o problema é integrador e motivador do estudo, o aprendizado passa a ser centrado no estudante, o professor atua para mediar grupos de trabalho ou estudo, nos quais a interação é intensa, dando ênfase à construção do conhecimento cooperativo (BARBOSA; MOURA, 2013, p. 58). "A ideia não é ter sempre o problema resolvido na etapa final do trabalho, mas sim enfatizar o processo seguido pelo grupo na busca de uma solução, valorizando a aprendizagem autônoma e cooperativa" (BARBOSA; MOURA, 2013, p. 58). O processo metodológico é sistemático, utilizando fases, com objetivos que podem ser definidos de comum acordo. Elaboramos, a partir da sistematização de Araújo (2011), um diagrama² para facilitar o entendimento:

\footnotetext{
${ }^{2}$ Este diagrama não é um modelo pronto e acabado, existem outras formas de sistematização, escolhemos este para facilitar a ilustração do percurso formativo.
} 


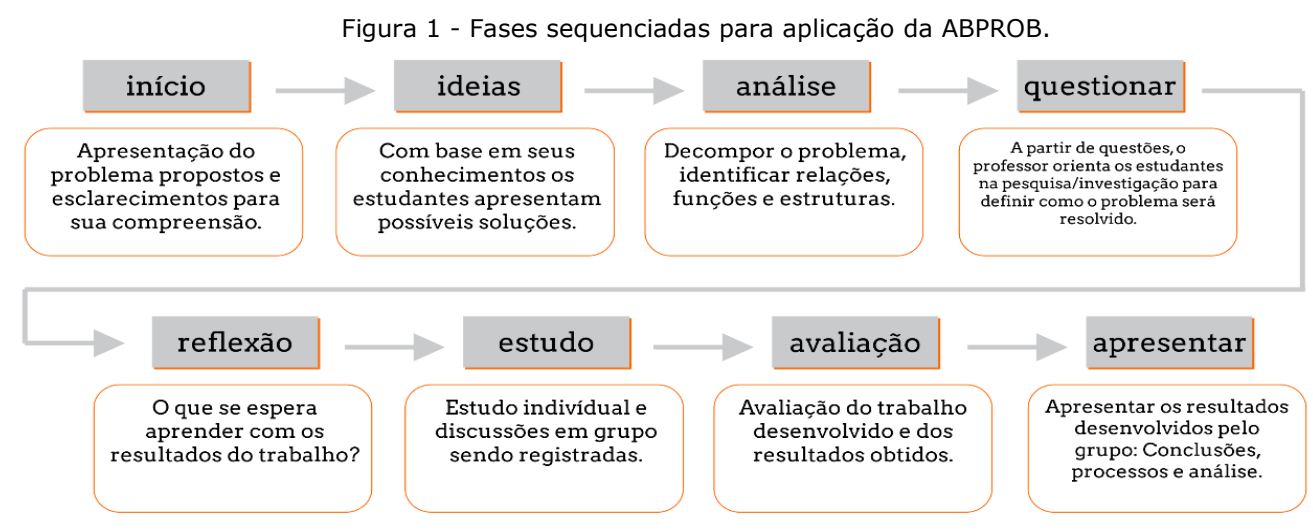

Fonte: Elaborada pelos autores com informações de Araújo (2011).

O professor propõe o problema integrador, podendo utilizar um documentário, vídeo ou mesmo um texto, o problema deve ser próximo da realidade dos participantes; os estudantes apresentam possíveis soluções baseadas em seus conhecimentos prévios; os estudantes são convidados a pensar mais sobre o problema, tentando entendê-lo a partir de diversos possíveis recortes, como algo mais complexo do que foi posto inicialmente; o professor então medeia a discussão por meio de questões norteadoras, com o objetivo de suscitar ainda mais a curiosidade dos estudantes sobre o tema; os estudantes elegem os objetivos de seus trabalhos a partir das reflexões sobre o tema; então, os estudantes começam a pesquisar utilizando diversos meios, desde pesquisa na internet, visitas de campo, recursos audiovisuais e compartilham suas descobertas com o grupo e o professor; os resultados dos conhecimentos obtidos e dos objetivos sobre o problema são avaliados em conjunto. O professor pode utilizar relatórios, apresentação oral, rubricas e outros mecanismos conjuntos de avaliação; os estudantes então apresentam sua abordagem conjunta sobre o tema, o processo de estudos e sistematização e os resultados obtidos com vistas à aquisição dos objetivos determinados pelo grupo, esses objetivos devem ser mais práticos, como a mudança da realidade anunciada ou mesmo um trabalho de conscientização acerca do problema estudado.

Utilizando ABPROB, o professor pode tratar de temas complexos apresentando, por exemplo, o "lixão" de sua cidade na forma de um problema que afeta o acesso aos moradores das áreas circunvizinhas aos bens e serviços proporcionados pela natureza, ou mesmo tratar das problemáticas de consumo, uma vez que essa categoria gera grande impacto na produção de "lixo" doméstico.

A ideia é que o professor não obtenha mais a função de especialista formal, trabalhando de forma isolada como transmissor do conhecimento, de conteúdos organizados em aulas expositivas e avaliando individualmente os estudantes. Ele age como mediador da situação problema, fomentando o trabalho em equipe e suscitando a aprendizagem e o trabalho interdisciplinar, organizado a partir de problemas reais do cotidiano dos estudantes: "o professor tem funções mais amplas e complexas do que nos métodos convencionais de ensino" (BARBOSA; MOURA, 2013, p. 60).

O estudante deixa então de ser um receptor passivo em uma aula baseada na transmissão de informações; transcrever, memorizar e repetir os conteúdos para se sair bem em uma prova não tem mais tanto sentido, a avaliação não é somativa e apenas realizada pelo professor. O objetivo é que o estudante tenha valorizado seu conhecimento prévio, possa interagir com colegas e professores, que o ambiente cooperativo e o problema apresentado fomente um espaço onde este possa analisar, questionar, sistematizar e solucionar problemas de forma a contribuir com o seu desenvolvimento cognitivo. Na ABPROB, a atividade formativa dá-se na busca de soluções, em que o conhecimento adquirido pode ser utilizado em vários contextos a partir da mediação 
docente, ela se desenvolve com base na resolução de problemas propostos, com a finalidade de que o aluno estude e aprenda determinados conteúdos (BERBEL, 2011, p. 32).

A ABPROB deve garantir ao estudante um aporte na busca de conhecimentos para resolução de situações problema, "A esfera cognitiva do PBL deve garantir que o aluno estude situações suficientes para se capacitar a procurar o conhecimento por si mesmo quando se deparar com uma situação problema ou um caso clínico" (BERBEL, 2011, p. 32).

Este processo, contudo, não pode ser pensado para uma ou duas aulas, na verdade, ele exige tempo de maturação e reflexão, além de uma adaptação da instituição às novas necessidades dos participantes: Estimular o estudante a interagir com o problema requer alguma aula de campo para pesquisa e investigação, espaços diferenciados para que os grupos possam se encontrar e discutir, bibliotecas para que possa haver consulta e preparação dos bibliotecários quanto à necessidade de informação destes como usuários, o uso de laboratórios para algum tipo de análise que estes desejem fazer e o acompanhamento técnico caso necessário (BARBOSA; MOURA, 2013, p. 60). Além das necessidades institucionais concretas, existem outros requisitos institucionais necessários no âmbito do currículo, oferta e sistematização das disciplinas.

A ABPROJ surge no final do século XIX, a partir das contribuições de John Dewey, em 1890. Ele "considerava que os projetos realizados por alunos demandam necessariamente a ajuda de um professor que pudesse assegurar o processo contínuo de aprendizagem e crescimento" (BARBOSA; MOURA, 2013, p. 60).

A aprendizagem baseada em projetos é

definida pela utilização de projetos autênticos e realistas, baseados em uma questão, tarefa ou problema altamente motivador e envolvente, para ensinar conteúdos acadêmicos aos alunos no contexto do trabalho cooperativo para a resolução de problemas (BENDER, 2014, p. 16).

Diferente da $A B P R O B$, o objetivo é que o grupo seja capaz de criar um possível projeto para construir, investigar ou explicar um problema.

Um projeto construtivo visa a inovação para a solução de um problema, seja na forma, na função ou no processo, buscando formas de resolução para o problema; um projeto investigativo utiliza de métodos científicos para a melhor compreensão do problema; já um projeto explicativo tem como objetivo responder a questões sobre um problema, buscando explicar, ilustrar, revelar princípios, mecanismos e sistema do objeto em análise (BARBOSA; MOURA, 2013, p. 63, grifo nosso).

Esse esforço para organizar projetos em torno de situações reais torna o estudante protagonista de sua aprendizagem através de uma experiência de educação autêntica, utilizando tarefas que os estudantes são solicitados a concretizar no mundo a sua volta, sendo uma característica comum a todas as abordagens da ABPROJ, aumentando a motivação dos estudantes (BENDER, 2014, p. 17). Para compreender melhor, sintetizamos, a partir dos estudos de Bender (2014, p. 61), um diagrama explicativo: 
Figura 2 - Fases sequenciadas para aplicação da ABPROJ.

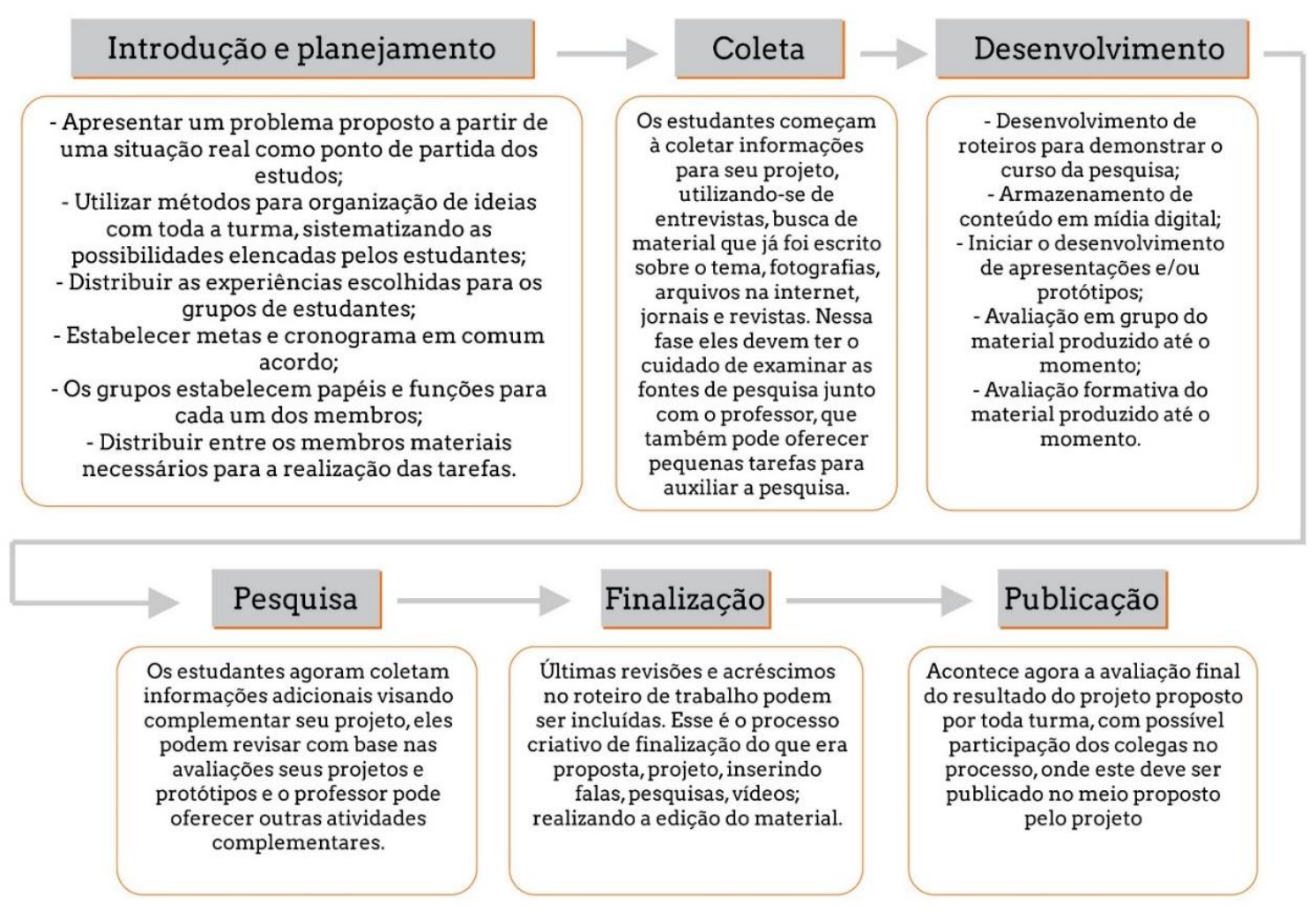

Fonte: Elaborada pelos autores com informações de Bender (2014, p. 61).

O professor inicia a atividade apresentando o tema a partir de situações reais, podendo utilizar filmes e outras mídias. Em seguida, ele se utiliza de ferramentas para organização de ideias, como mapas mentais, Design Thinking ${ }^{3}$ e brainstorm ${ }^{4}$, sistematizando os possíveis projetos que podem ser vídeos, blogs, páginas de wiki, algum tipo de equipamento físico, sistema informatizado, um livro, uma exposição fotográfica, portfólio, entre outros; os estudantes, em grupos, escolhem os projetos de que desejam participar; divididos os possíveis projetos, são pactuadas metas e o cronograma das atividades; são divididas funções e papéis para cada um dos membros; são distribuídos então entre os membros o material de apoio inicial, geralmente provido pelo professor, com preparação prévia.

Passado este momento inicial, os estudantes iniciam a coleta dos dados necessários, o que pode envolver entrevistas, visitas de campo, coleta de materiais, possíveis orçamentos, busca de textos e dados na internet, sempre tomando o cuidado de apresentar as fontes para 0 professor, para que juntos avaliem a credibilidade do material. Notemos que a ABPROJ pode associar-se facilmente aos projetos de ensino, pesquisa e extensão em Universidades ou a projetos comunitários, mais propriamente o caso de escolas (BERBEL, 2011, p. 31).

\footnotetext{
${ }^{3}$ Design Thinking é um processo de organização de ideias para a criação de um produto ou solução de um problema sistematizado nas etapas: definir o que se deseja realizar, pesquisar, gerar ideias, testar protótipos, selecionar, implementar e aprender. Ver Ambrose e Harris (2011).

${ }^{4}$ Brainstorm é uma ferramenta cooperativa utilizada para sistematizar um grande número de ideias sobre um tema previamente selecionado, também chamado de tempestade de ideias, ela foi creditada a Alex F. Osborn, em 1939, quando este era presidente de uma agência de propaganda. Ver Meireles (2001).
} 
Os estudantes então, com material em mão e ideias postas, criam um roteiro para ilustrar o curso do projeto, demonstrando o quão próximos estão de atingir as metas propostas; eles começam a preparar suas apresentações e/ou protótipos; são apresentados resultados preliminares e, em conjunto com o professor, todos participam do processo de avaliação. Com os resultados postos, novas abordagens de pesquisas são efetuadas visando melhorar o produto final, corrigir problemas e ampliar dimensões enunciadas na avaliação conjunta; em seguida, o produto final é preparado para apresentação. Por fim, o produto é apresentado para toda a classe e todos podem participar da avaliação, é um momento de interação entre os projetos realizados, em que o estudante vê seu projeto finalizado e arguido por colegas e professor. Então, o projeto é publicado no meio proposto.

Por ser uma metodologia mais sistemática, o professor tem, a toda hora, oportunidades de ministrar algum conteúdo programático, podendo utilizar a aula expositiva propositiva para as necessidades dos projetos, além disso, proporcionar, geralmente, com a ajuda de parceiros externos, cursos de formação para edição de vídeo, livros, cartilhas, apostilas e páginas de internet, onde os projetos acabam por instigar os estudantes a aquisição de novas habilidades e a formação de outras competências.

"Com a implementação desta estratégia, os estudantes definem como finalidade a criação de um produto, identificando seu mercado, investigando problemas, criando um plano de gestão e a concepção do projeto para desenvolver este produto" (RODRIGUEZ-SANDOVAL; VARGASSOLANO; LUNA-CORTES, 2010, p. 16, tradução nossa), todas estas fases requerem conhecimentos prévios que, associados ao uso de tecnologias, da mediação da informação por parte do professor, da investigação e da sistematização, proporcionam um espaço de aprendizagem significativa tendo em vista que o estudo se relaciona com seus objetivos e o estudante participa de todo o processo, estando envolvido em todas as suas fases (GADOTTI, 1994).

As duas metodologias ativas aqui apresentadas têm percursos comuns, para compreendermos melhor, segue um diagrama com as similaridades e diferenças entre os dois métodos:

Figura 3 - Diferenças e similaridades entre as metodologias apresentadas

\begin{tabular}{|c|c|}
\hline Aprendizagem baseada em problemas & Aprendizagem baseada em projetos \\
\hline Tem origem em Problemas & $\begin{array}{l}\text { Situação-geradora (Problemas, necessidades, } \\
\text { oportunidade, interesse, etc.) }\end{array}$ \\
\hline Problema: mais contextual do que teórico & Situação geradora: contextual ou teórica \\
\hline $\begin{array}{l}\text { Problemas definidos pelo professor (garante } \\
\text { cobertura de conteúdos de interesse do Curso/ } \\
\text { professor) }\end{array}$ & $\begin{array}{l}\text { Situação geradora/problemas definidos pelos } \\
\text { alunos mediados pelo professor (maior potencial } \\
\text { de motivação dos alunos) }\end{array}$ \\
\hline Curta duração (2 a 4 semanas) & Média duração (4 a 12 semanas) \\
\hline Percurso com etapas bem definidas & Percurso com etapas mais abertas e flexíveis \\
\hline Proposta de análise/solução de um problema & Proposta de desenvolver algo novo \\
\hline Produto final não obrigatório & Requer um produto final \\
\hline \multicolumn{2}{|c|}{ Formação efetiva para o mundo do trabalho } \\
\hline \multicolumn{2}{|c|}{ Favorece aprendizagem contextualizada e significativa } \\
\hline \multicolumn{2}{|c|}{ Requer disposição e habilidades específicas do professor e do aluno } \\
\hline \multicolumn{2}{|c|}{ Método de ensino centrado no aluno } \\
\hline \multicolumn{2}{|c|}{ Favorece a interdisciplinaridade } \\
\hline \multicolumn{2}{|c|}{ Favorece o desenvolvimento da criatividade e inovação } \\
\hline
\end{tabular}

Fonte: Adaptação feita por Barbosa e Moura (2013, p. 64) 
Os dois métodos se diferenciam quanto à possibilidade de origem dos questionamentos, sua abordagem (na relação teoria e prática) e sua escolha, na duração, na sistematização das fases, na proposta e na finalidade. Ambos estão ligados ao mundo do trabalho, à educação contextualizada e significativa, requerendo de estudantes e professores uma abordagem que possibilite a interdisciplinaridade e a criatividade com práticas centradas no estudante.

Compreendemos a ABPROB e ABPROJ como possibilidades de fomentar um interesse contínuo sobre os temas abordados nas disciplinas, possibilitando a participação, facilitando discussões teóricas; apresentando problemas que exigem tomada de decisão, capacidade de análise do ambiente a sua volta (CONRADO, 2014; SILVA; SOUZA; SEGURA, 2014; PEDROSA; JOÃO, 2013; ROSA, 2012; DINIZ et al., 2010; COURELA; CÉSAR, 2006). Entretanto, o que as experiências de aplicação têm a nos demonstrar sobre estas metodologias ativas?

\section{Experiências em ABPROB e ABPROJ}

Os relatos de experiência sobre a implementação dos métodos de problemas e projetos são ricas fontes para que possamos ter ideia dos limites e possibilidades de aplicação das metodologias ativas. Elencamos um total de dez estudos empíricos, os cinco primeiros sobre $A B P R O B$ e cinco seguintes sobre ABPROJ, a título de exemplo, que demonstram os resultados observados pelos pares na aplicação das metodologias.

$\mathrm{Na}$ implementação em uma universidade paulista, no curso de Administração de Empresas, Orochovicius e Tortella (2014) apontam que a experiência de implementação da ABPROB insere os estudantes numa realidade próxima ao mercado de trabalho, fomentando o desenvolvimento de conceitos, procedimentos e atitudes ante aos problemas reais, valorizando a autonomia dos estudantes e tendo como limites o entendimento dos professores quanto aos aspectos filosóficos e teóricos do método, bem como o cuidado no aprofundamento dos conteúdos e das ferramentas utilizadas no processo de ensino-aprendizagem.

Avaliando a percepção dos estudantes do curso de Medicina do Centro Universitário Serra dos Órgãos (UNIFESO), quanto à implementação do método de problemas; Smolka, Gomes e Siqueira-Batista (2014) apresentam como limites no uso do método a necessidade de aprofundamento dos conteúdos do ciclo básico, bem como, enumeram como ganhos aos estudantes o desenvolvimento da autonomia, na participação ativa nas aulas, em que o incentivo e respeito docente foram imprescindíveis para que os futuros profissionais possam rever seus papéis, posturas e posicionamentos objetivando a construção do conhecimento.

Durante o processo de implementação da $A B P R O B$ em um curso de Administração de empresas; Guedes, Andrade e Nicolini (2015) apontam que para os professores seu conhecimento prévio sobre as metodologias ativas foi fundamental e, comparativamente a outras turmas, houve um maior aproveitamento dos conteúdos trabalhados além de maior autonomia dos estudantes. Os principais limites apresentados foram a institucionalização, o conteúdo engessado dos professores acostumados á transmissão passiva de conhecimentos, correlacionar os conteúdos com os problemas a serem resolvidos, a divisão de tarefas e do trabalho em grupo por parte dos estudantes (GUEDES; ANDRADE; NICOLINI, 2015).

Existem também experiências de implementação da aprendizagem baseada em problemas na Educação a Distância (EAD). Na experiência de Bizarria, Tassigny, Bastos, Oliveira (2013), o relato demonstra como principais potencialidades da ABPROB a aprendizagem de forma contextualizada, incentivando a construção do conhecimento a partir de práticas laborais, que tornam atrativos e mais flexíveis o uso de diversas ferramentas, bem como o desenvolvimento de habilidades úteis ao mundo do trabalho, como a colaboração e a mediação de situações problema entre os participantes. Para este processo, na EAD, é indispensável o trabalho do tutor para o desenvolvimento do estudante, que deve ter uma postura reflexiva e aberta ante a imposição de regras rígidas através da mediação, tendo em mente que é equivocado pensar que 
esse trabalho é facilidade em virtude da capacidade de transmissão do conhecimento (BIZARRIA; TASSIGNY; BASTOS; OLIVEIRA, 2013).

Almeida, Camargo, Camargo (2017) nos apresentam os resultados de outra experiência da aplicação da ABPROJ em um curso de graduação em Ciências Sociais na modalidade EAD. Os principais limites percebidos foram a internet de má qualidade, os computadores precários, os estudantes que demonstraram uma certa resistência à utilização do método, bem como conflitos e a acepção da necessidade de conhecimentos prévios (ALMEIDA, CAMARGO, CAMARGO, 2017). A eficiência da aplicação se deu ao ofertar uma visão mais global dos conteúdos, propiciando o desenvolvimento e o exercício de um repertório considerado importante para acadêmicos da licenciatura, e ainda, destaca-se que a estratégia sensibilizou os estudantes quanto a sua atuação profissional, onde alguns demonstraram interesse na aplicação da metodologia (ALMEIDA, CAMARGO, CAMARGO, 2017).

No estudo sobre aplicação da ABPROJ de Campos (et al., 2013) com estudantes do $1^{\circ}$ semestre da graduação em Engenharia, os projetos estruturados foram realizados graças a objetivos pré-determinados, onde o papel da coordenação para o planejamento foi evidenciado bem como o dos professores, tendo como fator limitante o papel dos tutores no processo e a expectativa de apoio aos estudantes, que devem ser revistas.

Aplicando a ABPROJ na disciplina de interação humano e computador de curso de engenharia de software; Sales, Del, Sales (2013), destacam como principais pontos positivos da metodologia a satisfação dos participantes e a percepção de autoaprendizagem, enquanto o principal limite percebido está em lidar com problemas de relacionamento entre os participantes.

A experiência de Oliveira (2013), no curso online de Ciência dos Alimentos, constata que o método pode ser utilizado tanto em ensino presencial como a distância, onde as tecnologias educacionais tiveram papel de destaque na interação entre os diversos grupos participantes, já que a experiência contou com a participação de 12 Estados. Entre os pontos positivos se destacam o compartilhamento de experiências e ideias, o acréscimo na aprendizagem e no desenvolvimento de habilidades, valorização dos momentos de discussão; aos educadores participantes da EAD permitiu uma maior apreensão das relações interpessoais, liderança e proatividade, a partir de ideias e culturas distintas (OLIVEIRA, 2013). Entre os limites salientados temos o tempo de dedicação ao projeto em função da demanda de pesquisa e reflexão; problemas de interação, sobretudo nos grupos off-line; surgiram problemas de autoconfiança dos participantes, com demanda de acompanhamento e tutorias extras (OLIVEIRA, 2013).

Em uma escola de Educação profissional no interior do Ceará, cidade de Acopiara, Menezes e Rodrigues (2015) investigam o uso de ABPROJ correlacionada aos temas de educação ambiental, onde aparecem em destaque a compreensão do tema sustentabilidade, não obstante, os limites dessa aplicação ficam relacionados à institucionalização, a baixa interdisciplinaridade das ações na escola, que necessita desenvolver estratégias para ampliar a participação dos estudantes para além dos momentos das aulas expositivas-dialogadas.

Schneider, Zanette e Cechella (2016) investigam o uso da ABPROJ no âmbito da EAD, em uma disciplina de elaboração de um projeto-diagnóstico comercial em empresas, onde o nível de satisfação com seu desempenho, o uso de materiais e recursos, e o desempenho docente são percebidos como positivos pelos estudantes; ao passo que a dificuldade para realizar trabalhos em grupo e a gestão do tempo se apresentam como principais limites para esses participantes. Para os professores, o volume de atividades geradas e sua avaliação, devolução e reavaliação são os principais pontos negativos, no entanto, estes demonstram, em suas percepções que a qualidade da produção acadêmica, a gestão dos trabalhos, o desenvolvimento da mediação, a resolução de conflitos e o desenvolvimento da relação teórico-prática pelos estudantes são pontos positivos (SCHNEIDER; ZANETTE; CECHELLA, 2016).

Estes estudos demonstram que, nas experiências analisadas, se sobressai a autonomia do estudante e a aproximação do mundo do trabalho, assim como evidenciados por Berbel (2011), onde variadas habilidades e competências foram exploradas em um horizonte pragmático. Os 
limites apontados pelos estudos estão ligados a participação, que pode ser problemática para estudantes iniciantes, de acordo com certos temas e disciplinas; bem como a realização de trabalhos em grupo, que aparece como fator limitante, gerando instabilidade quando da mediação das contradições entre os participantes, onde o tempo e o volume de trabalho, tanto para discentes como docentes, também se representa como entrave.

Partindo do princípio que o professor conhece a realidade educativa de sua sala de aula, na posição de autoridade do conhecimento (FREIRE, 1996), os limites e possibilidades dessa realidade são percebidos em sua experiência profissional, cotidiana, neste ponto o professor tem uma melhor ideia de suas necessidades ante aos desafios reais. Assim, a utilização e aplicação, plena ou parcial, da ABPROB e ABPRJ devem ser flexíveis e condizentes com sua apreensão da realidade, não tomadas como uma panaceia que vem a resolver todos os problemas. Estas metodologias ativas devem ser encaradas como estruturas flexíveis as quais o professor não deve se agarrar como muletas, mas antes, a partir de sua prática profissional, compreender seus princípios filosóficos e teóricos na acepção de uma escolha deliberada entre usar, não usar, escolher o que vai usar e como vai aplicar. Caso julgue necessário, por exemplo, realizar aulas expositivas em meio à aplicação de um dos métodos, é sua experiência e sensibilidade a seu contexto de atuação, e não um aporte teórico, que deve conduzir o processo de ensinoaprendizagem.

As metodologias ativas não apresentam uma inovação surreal, capaz de mudar o mundo, elas surgem da experimentação e da experiência de profissionais da educação que buscam atingir outros aspectos didáticos que não eram possíveis utilizando-se apenas aulas expositivas, tratase de um movimento que tenta se aproximar da realidade educacional com uma série de limites e possibilidades a serem explorados.

\section{Aproximações teóricas}

As metodologias ativas ABPROB e ABPROJ ofertam algumas pistas para mudar nossas práticas, visando uma educação significativa, capaz de alinhar nossa base de pensamento a formas tidas como inovadoras de educar.

Outra pista que se alinha às metodologias ativas estudadas é a aprendizagem cooperativa (ACOOP) que, na prática, "passou a significar que os estudantes trabalham em pares ou em pequenos grupos para alcançar objetivos comuns de aprendizagem" (BARKLEY; MAJOR; CROSS, 2007 , p.18, tradução nossa), eles aprendem através do trabalho em grupo, compartilhando seus resultados, em que todos aprendem com todos, sendo que

\footnotetext{
A aprendizagem cooperativa garante maneiras diferentes para que os estudantes trabalhem de forma associativa, que eles aprendam uma variedade de habilidades sociais, que seu trabalho em grupos permaneça no caminho certo e que cada aluno contribua de forma equitativa com esse trabalho (BRUFFEE, 1995, p. 16, tradução nossa).
}

Nesse processo, o estudante não é só responsável pelo seu próprio aprendizado, mas também toma parte na responsabilidade do aprendizado do outro e do seu próprio (BARKLEY; MAJOR; CROSS, 2007, p.21).

$A$ ABPROB e ABPROJ apresentam uma mudança didática, portanto uma mudança de processo, a ACOOP propõe uma mudança de abordagem. ABPROB e ABPROJ apresentam limites justamente quanto ao trabalho em grupo, esses limites acabam tendo uma proximidade teórica com a abordagem da ACOOP.

Entre as características da ACOOP, está o trabalho cooperativo intencional. O educador propicia atividades cooperativas para as turmas e/ou grupos de estudantes, os quais se comprometem a trabalhar em grupo e socializar o aprendizado; sendo as tarefas pensadas para 
atingir os objetivos educacionais, diretamente ligados ao currículo (BARKLEY; MAJOR; CROSS, 2007, p.18-19).

Os elementos cruciais da ACOOP estão para além de manter-se fisicamente no mesmo local, discutindo materiais e auxiliando os estudantes ante as dificuldades apresentadas, este processo deve ser estruturado a partir de (SMITH, 1996, p. 75-76):

a) Interdependência positiva - chave do processo, os participantes dividem o sentimento de que o trabalho em grupo é central para o sucesso do processo, os estudantes devem se perceber juntos, com recompensas comuns, recursos e papéis compartilhados;

b) Promoção da interação face-a-face - os estudantes devem interagir auxiliando uns aos outros no cumprimento das tarefas, discutir entre eles os problemas e os conteúdos, auxiliando e encorajando os demais colegas;

c) Responsabilidades individuais e responsabilidades pessoais - o objetivo é tornar cada membro do grupo mais forte, aprendendo em conjunto, para posteriormente atuar como indivíduos, podem ser utilizados exames individuais socializados com o grupo, para que todos possam entender suas dificuldades individuais e corrigir os rumos dentro do próprio grupo, cada pessoa é responsável por uma pequena porção do trabalho e a socialização destes estudos;

d) Habilidades para o trabalho em grupo - habilidades como liderança, tomada de decisão, comunicação, gerenciamento de conflito são habilidades necessárias à vida dos estudantes, devem ser favorecidas e pensadas para serem aproveitadas dentro dos trabalhos propostos;

e) Processo coletivo - o educador deve assegurar que todos os membros também discutam o quão bem estão alcançando seus objetivos, para manter relações efetivas no processo, facilitando o reconhecimento de habilidades e competência por parte de seus integrantes bem como a manutenção do grupo, a partir da discussão crítica da atuação de todos, visando o sucesso do processo.

Dessa forma, o processo de ACOOP se inter-relaciona com o ensino, exigindo algumas mudanças, tanto na atitude do educador como em processos de gestão educacional, como no caso do currículo, visando fortalecer laços entre os participantes que coordenam juntos sua construção coletiva do conhecimento.

Compreendemos assim que a "aprendizagem cooperativa, portanto, envolve dois ou mais estudantes trabalhando juntos e compartilhando de forma equitativa as atividades à medida que progridem em direção aos resultados de aprendizagem esperados" (BARKLEY; MAJOR; CROSS, 2007, p.19), não sendo apenas uma forma para que grupos enormes de trabalho se estabeleçam, mas sim, estabelecidas a partir da ideia de que juntos podemos aprender melhor. O sentido de individualização, dentro deste processo, está em respeitar o ritmo de cada participante e sua independência do todo, ao mesmo tempo em que se promove o trabalho cooperativo e o interesse do coletivo (ALMEIDA, 2011, p. 49).

Existe, portanto, uma aproximação teórica possível na abordagem da ACOOP (SMITH, 1996) com $A B P R O B$ e $A B P R O J$, as habilidades para o trabalho em grupo se aproximam dos preceitos da formação efetiva para o mundo do trabalho (BARBOSA; MOURA, 2013) por valorizar uma série de habilidades e competências no processo de formação que serão úteis aos participantes quando inseridos no mundo do trabalho.

A valorização de processos interdisciplinares e o favorecimento do trabalho coletivo nas metodologias ativas se interligam às responsabilidades individuais e pessoais, às habilidades para o trabalho em grupo e a processos criativos, primordialmente na construção do conhecimento, mas também por fomentar espaços seguros onde possam ser estabelecidas relações com o conhecimento.

ABPROB e ABPROJ têm em sua concepção a cooperação para a construção do conhecimento, não obstante, pensar a partir das estruturas didáticas requer uma abordagem intencional da ação a ser construída, essa é a principal possível contribuição da ACOOP. Mediar processos cooperativos na educação exige ao profissional da educação uma reflexão que leve a sensibilizar os estudantes sobre a necessidade cooperativa para a construção do conhecimento visando uma 
ação interdisciplinar frente a essa construção que corrobore com os objetivos propostos em se aplicar metodologias ativas (ANTUNES et al., 2016; ANTUNES; NASCIMENTO; QUEIROZ, 2018).

Quando perquirimos sobre o conceito e as experiências, bem como resultados apresentados em investigações cientificas sobre o tema, nos deparamos com algumas variações na nomenclatura, e ainda, variações de concepção teórico-prática da utilização da ACOOP.

Em nível de processo, a aprendizagem se dá através das relações sociais, e essas relações variam de acordo com idade e cultura do grupo, cabe-nos diferenciar o conceito quanto a participação. Os autores sugerem dois âmbitos, o da ACOOP e o da aprendizagem colaborativa (ACOL), o primeiro "exige que os alunos trabalhem juntos em uma tarefa comum, compartilhem informações e se apoiem mutuamente" (BARKLEY; MAJOR; CROSS, 2007, p.18), tendo a primazia do encontro e do compartilhamento, o que enseja em espaços de menor conflito, uma vez que o princípio se torna a compartilhar ideias e informações, sendo ideal para o ensino infantil, por ser um período de desenvolvimento da criança, onde a formação de comunidades educativas colaborativas auxilia nas interações sociais entre as crianças (BRUFFEE, 1995).

A ACOL compreende a extensão do conflito nas relações sociais, ela parte do princípio de sua eminência, onde a tomada de decisão dialógica, por meio da mediação para a chegada ao consenso estabelece sua primazia, com "base no fato de que o conhecimento é produzido socialmente por consenso entre colegas versados na matéria" (BARKLEY; MAJOR; CROSS, 2007, p.19). Acerca deste ponto, os autores destacam que a ACOL é melhor aplicada na educação superior, tendo em vista a diversidade de ideias e interações neste espaço educativo, bem como a diversidade de informações, que são melhor aproveitadas em espaços de discussão, mediação e busca de consensos valorizando as contradições formadas nestes grupos sociais e a mediação destas para a construção colaborativa do conhecimento (BARKLEY; MAJOR; CROSS, 2007; BRUFFEE, 1995).

Resumidamente, a ACOOP busca reduzir a eminência dos conflitos ocasionados pelas contradições existentes no grupo, enquanto a ACOL evidencia estas contradições buscando sua resolução, por meio da mediação, para a construção de consensos dentro do grupo.

Mantém-se a ideia geral do trabalho em grupo como propulsor da educação, onde "o ambiente colaborativo permite a utilização das conexões para a resolução conjunta de problemas e a produção de novos conhecimentos" (COLOSSI; CONSENTINO; DE QUEIROZ, 2017, p. 55), mas é acrescida a tal pensamento, a ideia de que, em espaços colaborativos, o respeito às diferenças e a mediação das contradições na construção do conhecimento, resultante da diversidade de interações sociais, contribua para o processo de ensino-aprendizagem.

Bruffee (1995) estabelece alguns pontos essenciais, que devem ser levados em consideração para o bom andamento da $A C O L$, onde o exercício das relações de poder e a tomada de decisão dos estudantes está em suas mãos, eles têm o poder decisório; o professor deve tentar intervir pouco e em situações bem específicas nos grupos; a avaliação deve ser centrada na aplicação do que foi aprendido e não na relação entre os parceiros; sendo a lição mais importante que

A aprendizagem colaborativa pressupõe a resistência as tarefas, a rebelião contra o professor e o questionamento dos pontos de vista uns dos outros, dentro de um grupo, podem ser inevitáveis e, muitas vezes, aspectos necessários da aprendizagem (BRUFFEE, 1995, p. 17, tradução nossa).

O educador atua como mediador do processo, ele é a autoridade do conhecimento, no início, mas deve possibilitar que, a partir das interações sociais e da construção coletiva do conhecimento, dentro das contradições eminentes no próprio grupo, se possa se atingir os objetivos educacionais.

Existe então um rearranjo processual, onde há disposição para colaborar, o educador atua diretamente com os estudantes fornecendo apoio, no entanto, a figura do educador e os objetivos se abrem para tais interações compreendendo a complexidade do todo e a contribuição das contradições mediadas como necessárias ao processo de ensino-aprendizagem. 
Os princípios didáticos da ACOOP e ACOL se estendem, em nosso entendimento, aos quatro pilares da educação propostos por Delors (2012): a) A aprender a conhecer - o processo de ensino-aprendizagem deve buscar ampliar os saberes, despertar a curiosidade, estimular o senso crítico, auxiliando o estudante a adquirir uma maior e progressiva autonomia; b) Aprender a fazer - sendo necessário um equilíbrio entre atividades práticas e teóricas, buscando a resolução de problemas, a aplicação daquilo que se compreender ao estudar; c) Aprender a conviver estimulando os aspectos sociais e aquisição da dimensão moral e apropriada; e d) Aprender a ser - que inclui as dimensões anteriores, na garantia de uma aprendizagem global, incluindo o corpo e a mente, a inteligência, o sentido estético, a responsabilidade individual e espiritual, possibilitando a compreensão, por parte do estudante, da complexidade de suas expressões e seus comprometimentos (individuais e coletivos) (ALMEIDA, 2011, p. 47-48).

Quando atingidos satisfatoriamente estes elementos, em consonância aos elementos centrais do tipo educativo, o estudante pode tomar consciência da importância de tais métodos em seu processo educativo, contribuindo para sua formação, respectivamente, no plano inter-psicológico (mediado pela influência dos outros) e intra-psicológico (uma vez interiorizado o conhecimento), onde o estudante tem a possibilidade de assumir o controle de sua própria atuação no processo de ensino-aprendizagem (ALMEIDA, 2011, p. 49).

Os vários pontos referentes às integrações referentes a $A B P R O B, A B P R O J, A C O O P$ e $A C O L$ estão orientados a novas possibilidades da ação pedagógica pautada na horizontalidade da relação educador-estudante. Repensar as possibilidades é ofertar, mediar e relacionar uma experiência mais próxima à realidade, onde podemos construir de forma cooperativa/colaborativa o conhecimento, através de escolhas claras e pactuadas, visando contribuir e aproximar os diversos campos a uma abordagem que comunique renovadas possibilidades de interação na construção do conhecimento.

\section{Conclusão}

Como métodos, a $A B P R O B$ e a ABPROJ se diferem quanto à finalidade e aos objetivos educacionais planejados pelos educadores. No entanto, apresentam uma matriz comum, sendo métodos que interagem com os conteúdos a partir de problemas que instigam os estudantes a serem protagonistas de sua resolução.

O ponto culminante destes processos se dá na centralidade do estudante, que é parceiro do educador na construção coletiva do conhecimento. Através da interação entre professor/mediador, estudante e estudantes se dá a construção social, com o objetivo de ampliar a autonomia do educando, fortalecida por processos de pesquisa, reflexão crítica e experimentação ligados à prática e aplicação dos conhecimentos.

O desenvolvimento a partir de habilidades e competências da equipe pode fortalecer 0 processo educativo. A variedade de projetos e/ou resolução de problemas pode cria uma atmosfera positiva que auxilia na aquisição das melhores formas de encarar o problema. Juntos, estudantes e professores podem (re)significar suas interações na escolha dos métodos e objetivos que melhor se enquadrem nas características únicas necessárias para a vida dentro do processo de ensino-aprendizagem.

A sistematização de ambas as metodologias se mostra necessária para que os educadores interessados em sua aplicação possam conhecer as nuances, perceber as diferenças de cada abordagem, reconhecer os limites e as possibilidades de uso, para que assim possam escolher entre o método que melhor se adequa a sua realidade e como esses métodos serão aplicados.

O principal limite se apresenta ao refletirmos sobre o papel do estudante no conjunto metodológico, a tomada de consciência se torna complexa, visto que os métodos tradicionais fazem parte da história de vida do estudante, tencionar a mudança é algo necessário para auxiliar o estudante a perceber que ele é o principal responsável por sua formação, sendo o professor apenas parte desta história de vida. 
As possibilidades são inúmeras, uma vez que a aplicação de novos e instigantes métodos educativos, mais significativos e contextualizados com a realidade do estudante tendem a proporcionar espaços mais pragmáticos, onde o conhecimento não é apenas memorizado, mas passível de aplicabilidade no mundo real. Os relatos sobre a ABPROB e ABPROJ demonstram que a autonomia, a possibilidade de colaboração e a aproximação com o mundo do trabalho são os principais ganhos dessas abordagens.

Não significa dizer, contudo, que não existirão mais problemas educacionais, mas que novos problemas surgirão, diferentes, que ainda devem causar ânsia aos educadores por sua resolução. A reflexão que o educador pode fazer, neste ponto, é "os meus atuais problemas, no âmbito da aula expositiva, estão atrapalhando o desenvolvimento da minha profissão e dos estudantes?", se a resposta for sim, o uso das metodologias aqui descritas podem oferecer condições para que o educador mude estes problemas radicais por outros, de mais fácil mediação, ou ainda, que escolha deliberadamente reunir ambas as formas, não é a teoria a priori, mas sua reflexão sobre a prática que guia seus processos de tomada de decisão.

A partir das aproximações teóricas discutidas, compreendemos que a ACOOP, como abordagem do processo educativo, possibilita um enlace com os métodos estudados, oportunizando uma valorização das habilidades e competências para a vida e o trabalho em grupo, fomentando processos criativos e interdisciplinares que podem ser motivados a partir da interdependência positiva, chave para o processo cooperativo.

Além de um processo didático e sistemático, a aplicação da ABPROJ e ABPROB tem em seu interim a necessidade ativa da cooperação. Nossa análise nos leva a compreender, portanto, que a abordagem proposta pela ACOOP/ACOL contribui no sentido de proporcionar aos estudantes uma maior integração.

Para estudos futuros, recomendamos a aplicação e adaptação dos métodos e abordagem, com relatos de experiência que informem as flexibilizações realizadas em espaços educativos e contribuem fortemente para a discussão, seja no âmbito profissional ou acadêmico, em que os resultados da atividade colaborem para a reflexão crítica sobre a aplicação destes métodos, seus limites e possibilidades, no âmbito de diferentes contextos educacionais.

\section{Referências}

ALMEIDA, Cláudia Regina Santos de; CAMARGo, Mônica Nogueira; CAMARGo, Luana Brito. Educação popular e aprendizagem baseada em problemas na EAD: Uma aplicação no curso de ciências sociais EAD/UNIMONTES. Revista Multitexto, v. 4 n. 2, 2017.

ALMEIDA, Marcos Teodorico Pinheiro de. Jogos Cooperativos: Aprendizagens, métodos e práticas. São Paulo: Fontoura, 2011.

AMBROSE, Gavin; HARRIS, Paul. Design Thinking: Ação ou prática de pensar o design. São Paulo: Bookman, 2011.

ANTUNES, Jeferson; LIMA, Jânio do Nascimento; TEIXEIRA, Wesley Castro; SOUSA; Lizandra de Barros de; CAVALCANTE; Samuel Onofre. Considerações e resultados acerca da aplicação da Criativa: metodologia educativa fomentada por meio dos jogos cooperativos. Cadernos de Pesquisa: Pensamento Educacional, Curitiba, v. 11, n. 27, p.15-33 jan./abr. 2016.

ANTUNES, Jeferson; NASCIMENTO, Verônica Salgueiro do; QUEIROZ, Zuleide Fernandes de. Educação para sustentabilidade, interdisciplinaridade e as contribuições da mediação para a construção coletiva do conhecimento. Rev. Eletrônica Mestr. Educ. Ambient. Rio Grande, v. 35, n. 1, p. 260-278, jan./abr. 2018.

ARAÚjO, Ulisses F. A quarta revolução educacional: a mudança de tempos, espaços e relações na escola a partir do uso de tecnologias e da inclusão social. ETD: Educação temática digital, Campinas, v. 12, 2011. Número especial. 
BARBOSA, Eduardo Fernandes; MOURA, Dácio Guimarães De. Metodologias ativas de aprendizagem na Educação Profissional e Tecnológica. Boletim Técnico do Senac : a Revista da Educação Profissional, Rio de Janeiro , v. 39, n. 2, p. 48-67, maio/ago. 2013.

BARKLEY, Elizabeth; MAJOR, C. Howell; CROSS, K. Técnicas de aprendizaje colaborativo: Manual para el profesorado universitario. Madrid: Ediciones Morata, 2007.

BENDER, William N.. Aprendizagem baseada em projetos: Educação diferenciada para o século XXI. Porto Alegre: Penso, 2014.

BERBEL, Neusi Aparecida Navas. As metodologias ativas e a promoção da autonomia de estudantes. Semina: Ciências Sociais e Humanas, Londrina, v. 32, n. 1, p. 25-40, jan./jun. 2011.

BIZARRIA, Fabiana Pinto de Almeida; TASSIGNY, Mônica Mota; BASTOS, Adriana Teixeira; OLIVEIRA, Artur Gomes de. Aprendizagem baseada em problemas em contextos de educação à distância. Revista EDaPECI: Educação a Distância e Práticas Educativas Comunicacionais e Interculturais, v. 13, n. 2, 2013.

BRUFFEE, Kenneth A. Sharing our toys: Cooperative learning versus collaborative learning. Change: The Magazine of Higher Learning, v. 27, n. 1, p. 12-18, 1995.

CALDEIRA, Camila Santana; GODOY, Marcela Teixeira; MORALES, Angélica Góis. A educação ambiental e a interdisciplinaridade no contexto escolar. In: Actas Congreso de Medio Ambiente AUGM, 7mo, 2012, ARGENTINA.

CAMPOS, Luiz Carlos de; LIMA, Rui M.; ALVES, Anabela Carvalho; MESQUITA, Diana; MOREIRA, Francisco; CAMPOS, Bárbara. Fatores críticos num processo de Aprendizagem Baseada em Projetos: percepções de estudantes de $1^{\circ}$ ano de Engenharia. In: 5th International Symposium on Project Approaches in Engineering Education (PAEE'2013). Universidade do Minho. Centro de Investigação em Educação (CIEd), 2013.

CRESWELL, John W. Projeto de pesquisa métodos qualitativo, quantitativo e misto. Porto Alegre: Artmed, 2010.

COLOSSI, Nelson; CONSENTINO, Aldo; DE QUEIROZ, Etty Guerra. Mudanças no contexto do ensino superior no Brasil: uma tendência ao ensino colaborativo. Revista da FAE, v. 4, n. 1, 2017.

CONRADO, Dália Melissa. Aprendizagem Baseada em Problemas (ABP) na Educação Científica como Estratégia para Formação do Cidadão Socioambientalmente Responsável. Revista Brasileira de Pesquisa em Educação em Ciências Vol. 14, No 2, 2014.

COURELA, Conceição; CÉSAR, Margarida. Promovendo a sustentabilidade: Uma experiência de partilha entre a escola e a comunidade envolvente. Revista Electrónica de Enseñanza de las Ciencias v. 5, n. 1, 2006.

DECKER, Isonir da Rosa; BOUHUIJS, Peter A. J.. Aprendizagem baseada em problemas e metodologia da problematização: Identificando e analisando continuidades e descontinuidades nos processos de ensino-aprendizagem. In: ARAÚJO, Ulisses F.; SASTRE, Genoveva. Aprendizagem baseada em problemas no Ensino Superior. 3ed. São Paulo: Sumus, 2016.

DELORS, Jacques. Educação um tesouro a descobrir: relatório para a Unesco da Comissão Internacional sobre Educação para o século XXI. 7ed. Brasília: Cortez, 2012.

DINIZ, Ana Paula; MARTINS, Reane Fonseca; HORTA, Maria Aparecida Ferreira; DEL CARMEN, Alicia. A utilização da metodologia da problematização na área da saúde: Uma estratégia para o ensino da temática ambiental. In: Seminário Nacional de Educação Tecnológica e Profissional, 2010, Minas Gerais. Anais do... Minas Gerais: IFMG, 2010.

ENEMARK, Stig; KJAERSDAM, Finn. A ABP na teoria e na prática: a experiência de Aalborg na inovação do projeto no ensino universitário. In: ARAÚJO, Ulisses F.; SASTRE, Genoveva. Aprendizagem baseada em problemas no Ensino Superior. 3ed. São Paulo: Sumus, 2016.

FREIRE, Paulo. Pedagogia da autonomia: Saberes necessários à prática educativa. 24ed. São Paulo: Editora Paz e Terra, 1996.

GADOTTI, Moacir. História das idéias pedagógicas. 2.ed. São Paulo: Ática, 1994. 
GUEDES, Karine de Lima; ANDRADE, Rui Otavio Bernardes de; NICOLINI, Alexandre Mendes. A Avaliação de estudantes e professores de administração sobre a experiência com a aprendizagem baseada em problemas. Administração: Ensino e Pesquisa, v. 16, n. 1, 2015.

MEIRELES, Manuel. Ferramentas administrativas para identificar observar e analisar problemas. São Paulo: Arte \& Ciência, 2001.

MENEZES, Jones Baroni Ferreira; RODRIGUES, Alzeir Machado. Sustentabilidade como tema de práticas pedagógicas na Escola Estadual de Educação Profissional Alfredo Nunes de Melo em Acopiara (CE). Revista Brasileira de Educação Ambiental (RevBEA), v. 10, n. 2, 2015.

MORIN, Edgard; CIURANA, Emilio-Roger; MOTTA; Raúl Motta. EDUCAR NA ERA PLANETÁRIA: O pensamento complexo como Método de aprendizagem no erro e na incerteza humana. São Paulo: Editora Cortez, 2003.

OLIVEIRA, Maria das Dores Rodrigues de. Project and problem-based learning on environment online in perspective teacher and students Food Science. 2013. 238 f. Tese (Doutorado em Ciência de Alimentos; Tecnologia de Alimentos; Engenharia de Alimentos) - Universidade Federal de Viçosa, Viçosa, 2013.

OROCHOVICIUS, Eli; TORTELLA, Jussara Cristina Barboza. Aprendizagem Baseada em Problemas: um método de ensino-aprendizagem e suas práticas educativas.Ensaio: aval.pol.públ.Educ., Rio de Janeiro, v. 22, n. 83 , p. 263-294, June 2014

PEDROSA, Maria Arminda; JOÃO, Patrícia. Aprendizagem Baseada em Resolução de Problemas na Educação em Ciências para a Sustentabilidade. In: Atas do Encontro sobre Educação em Ciências através da Aprendizagem Baseada na Resolução de Problemas. ISBN: 978-989-8525-26-0 | Braga, CIEd UMinho, 2013

RODRIGUEZ-SANDOVAL, Eduardo; VARGAS-SOLANO, Édgar Mauricio; LUNA-CORTES, Janeth. Evaluación de la estrategia "aprendizaje basado en proyectos". educ.educ. [online]. 2010, vol.13, n.1, pp.13-25. ISSN 0123-1294.

ROSA, Marina Maria Filipe. A metodologia de projeto na aprendizagem da biodiversidade e geodiversidade na praia da concha. 2012. $101 \mathrm{f}$. Dissertação de Mestrado (Programa de Mestrado em Ensino de Biologia e Geologia para o $3^{\circ}$ ciclo do Ensino Básico e para o Ensino Secundário) UNIVERSIDADE DE COIMBRA - FACULDADE DE CIÊNCIAS E TECNOLOGIA, Coímbra, 2012.

SALES, André Barros de; DEL, A. M.; SALES, M. B. Avaliação da aplicação da aprendizagem baseada em problemas na disciplina de interação humano e computador de curso de engenharia de software. RENOTE - Revista Novas Tecnologias na Educação, v. 11, n. 3, dez. 2013.

SCHNEIDER, Michele Domingos; ZANETTE, Elisa Netto; CECHELLA, Nara Cristine Thomé Palácios. Relato de experiência: Metodologia de aprendizagem baseada em projeto, em curso de graduação a distância. In: Edição especial do II Congresso Ibero-Americano de Humanidades, Ciências e Educação, 18 a 20 de maio de 2016.

SILVA, Gilson Gean Marcelo da; SOUZA, Irley Gondim de; SEGURA, Eduardo. Pedagogia de projetos: Resultados de uma experiência de educação do/no campo a partir do diálogo e interação de saberes no contexto rural amazônico. Revista de Ciências Humanas e Sociais da FSDB - ANO X, VOLUME XIX JANEIRO - JUNHO 2014

SMITH, Karl A.. Cooperative learning: Making "groupwork" work. in: Sutherland, Tracey; Bonwell,? Charles C.. New directions for teaching and learning. 1ed. Estados Unidos: Jossey-Bass, 1996.

SMOLKA, Maria Lúcia Rebello Marra; GOMES, Andréia Patrícia; SIQUEIRA-BATISTA, Rodrigo. Autonomia no contexto pedagógico: percepção de estudantes de medicina acerca da aprendizagem baseada em problemas. Rev. bras. educ. med., Rio de Janeiro, v. 38, n. 1, p. 5-14, Mar. 2014. 


\section{Jeferson Antunes}

Doutorando - programa de Pós-graduação em Educação da Universidade Federal do Ceará - PPGE/UFC, Brasil, jeferson.kalderash@gmail.com

\section{Verônica Salgueiro do Nascimento}

Professora adjunta - Universidade Federal do Ceará - UFC, Brasil, vesalgueiro@gmail.com

\section{Zuleide Fernandes de Queiroz}

Professora associada - Universidade Regional do Cariri - URCA, Brasil, zuleidefqueiroz@gmail.com 